\title{
Bacterial translocation, intestinal microflora and morphological changes of intestinal mucosa in experimental models of Clostridium difficile infection
}

\author{
P. NAABER, R.-H. MIKELSAAR*, S. SALMINEN† and MARIKA MIKELSAAR
}

Department of Microbiology, University of Tartu, Vanemuise 46, EE 2400, Tartu, *Institute of General and Molecular Pathology, University of Tartu, Estonia and †Department of Biochemistry and Food Chemistry, University of Turku, Finland

\begin{abstract}
Bacteraemia and subsequent sepsis is one possible complication of Clostridium difficile infection. The aim of this study was to examine a correlation between bacterial translocation with morphological changes of intestinal mucosa and shifts of intestinal microflora in experimental models of $C$. difficile infection. A mouse model was used to study post-antibiotic shifts and mild $C$. difficile infection, and hamsters were used to study fatal enterocolitis. The influence of pro- and pre-biotics (lactobacilli and xylitol) were also studied in the hamster model. The quantitative composition of luminal and mucosal microflora was evaluated in different intestinal loci, inflammatory changes of mucosa were estimated in histological sections and bacterial translocation was detected in samples from blood, liver, spleen and mesenteric lymph nodes. In cases of mild $C$. difficile infection, the extent of disturbance of intestinal microflora appeared to be a more important promoting factor in translocation than inflammatory activity in the mucosa. Translocation was frequent in fatal enterocolitis, with facultative species predominating in the intestinal mucosa and also $C$. difficile in some cases. The combination of lactobacilli and xylitol had some protective effect against $C$. difficile infection in these models.
\end{abstract}

\section{Introduction}

Clostridium difficile is the most frequent pathogen implicated in antibiotic-associated diarrhoea [1]. Depending on its virulence and the susceptibility of the host, this pathogen produces a wide spectrum of disease, ranging from self-limiting watery diarrhoea to fatal pseudomembranous colitis (PMC). Disruption of the stability of the host's indigenous microflora is a prerequisite for colonisation by $C$. difficile and subsequent infection. This alteration of colonisation resistance occurs mainly after antibiotic therapy in hospitalised patients. In cases of complicated PMC, colonic perforation, peritonitis and secondary infections - mainly due to bacteraemia - may result [2]. In spite of emergency surgical intervention and intensive

Received 3 Sept. 1997; revised version accepted 7 Nov. 1997.

Corresponding author: Dr P. Naaber. antimicrobial treatment these severe conditions are associated with high mortality [3].

In some patients with severe underlying disease, bacterial translocation from mucosal surfaces, particularly of the intestinal tract, is an important cause of bacteraemia and subsequent septic processes [4]. Intestinal bacterial translocation is the passage of viable indigenous bacteria from the gastrointestinal tract to the mesenteric lymph nodes, spleen, liver, peritoneal cavity and bloodstream [5]. The most frequent translocating organisms include Escherichia coli and other members of Enterobacteriaceae, but rarely anaerobes [4]. It has not been identified that micro-organisms translocate through $C$. difficile-damaged intestinal mucosa. An experimental model for such studies is needed urgently.

Several experimental animals have been used to study the pathogenesis of $C$. difficile-induced infections and its virulence factors, including guinea-pigs, rats, rabbits, mice and hamsters. The most frequently used 
animal model for studying severe $C$. difficile enterocolitis is the antibiotic-compromised hamster model, as hamsters are extremely sensitive to $C$. difficile toxins [6].

C. difficile diarrhoea can also be induced in cefoxitintreated conventional $\mathrm{BALB} / \mathrm{c}$ mice. Mice are relatively resistant to $C$. difficile toxins and the morphological findings in the colon during infection are similar to changes in the human intestine [6]. The mouse model of $C$. difficile infection has been used successfully for the investigation of histological changes in intestinal mucosa and shifts in intestinal microflora in animals fed different diets [7].

Experimental studies have shown that administration of antimicrobial agents and physical alteration of the mucosal barrier can enhance bacterial translocation from the intestinal tract. However, it is not known whether translocation correlates with histological changes in the intestinal mucosa and with shifts in the mucosal and luminal microflora after antibiotic therapy, or in the process of development of $C$. difficile infection. Nor is it known if probiotic administration can influence the spectrum of translocating organisms in pseudomembranous colitis.

The aim of this study was to determine whether it is possible to predict the type of bacterial translocation, given knowledge of the degree of inflammatory changes in the intestinal mucosa and the state of the intestinal microflora in experimental $C$. difficile infection.

\section{Materials and methods}

\section{Study design}

Several experimental clinical models were used to study the influence of possible alterations in intestinal microbial ecology important in the pathogenesis of antibiotic-associated diarrhoea: (1) antibiotic-compromised mice as a model of post-antibiotic shifts in the intestinal tract; (2) antibiotic-compromised and $C$. difficile-challenged mice as a model of mild $C$. difficile infection; (3) antibiotic-compromised and $C$. difficileinfected hamsters as a model of severe enterocolitis; and (4) antibiotic-compromised and $C$. difficile-challenged hamsters receiving xylitol and lactobacilli as a model of the putative influence of probiotics on $C$. difficile infection.

\section{Experimental animals}

Adult BALB/c mice $(n=22)$ were used in the mouse experiments. The mice were housed individually in stainless steel cages; the cages were sterilised before use and the bedding was changed daily. The mice were distributed into three groups: group 1 (seven mice) served as controls; group 2 (eight mice) received cefoxitin (Mefoxitin, MSD Sharp and Dohme GmbH), daily dose $100 \mathrm{mg} / \mathrm{kg}$ administered intragastrically with a stainless steel feeding tube for 5 days; group 3 (seven mice) received cefoxitin (similarly to group 2) and were inoculated with a virulent strain of $C$. difficile (ME 82) $24 \mathrm{~h}$ after the last antibiotic dose. Mice were killed with chloroform anaesthesia (group 2, $24 \mathrm{~h}$ after the last antibiotic dose; group 3, 5 days after challenge with $C$. difficile) and samples were taken from the ileum and colon for histological and bacteriological studies.

Nine adult Syrian hamsters (Mesocricetus auratus) were divided into two groups and kept in the same conditions as mice. Group 4 (four hamsters) received a single dose of ampicillin ( $3 \mathrm{mg}$ intragastrically) and were challenged with $C$. difficile (toxic strain VPI 10463) $24 \mathrm{~h}$ later. Group 5 (five hamsters) received ampicillin and $C$. difficile similarly to group 4 . This group also received Lactobacillus rhamnosus GG $(0.5 \mathrm{ml}$ of broth culture) and xylitol ( $1 \mathrm{ml}$ of $20 \%$ solution) intragastrically once daily, starting $20 \mathrm{~h}$ before administration of $C$. difficile. Asymptomatic hamsters were killed 5 days after challenge with $C$. difficile; moribund hamsters were also killed. Samples for bacteriological and histological studies were taken from ileum, caecum and colon of killed or freshly deceased hamsters. Samples of blood, mesenteric lymph nodes (MLN), spleen and liver were also taken from all mice and hamsters for detection of bacterial translocation.

\section{Bacterial strains}

A toxigenic strain of $C$. difficile ME 82 was isolated from a patient with PMC in Tampere University Hospital, Finland. The highly virulent strain VPI 10463 was kindly given to us by the Microbiology Department at the University of Turku. The bacterial inoculum for use in the animal model was prepared by incubating the strains of $C$. difficile anaerobically at $37^{\circ} \mathrm{C}$ for $24 \mathrm{~h}$ in Columbia Broth (BBL). The culture was centrifuged $(3000 \mathrm{rpm}$ for $10 \mathrm{~min})$ and resuspended in an equivalent volume of saline (c. $10^{8} \mathrm{cfu} / \mathrm{ml}$ ) and $0.5 \mathrm{ml}$ of microbial suspension was given to animals intragastrically.

L. rhamnosus strain GG (ATCC 53103) was kindly provided by Valio Ltd, Finland. A dose of $0.5 \mathrm{ml}$ of a 24-h-old culture in MRS Broth (Oxoid) was administered to hamsters intragastrically.

\section{Histological samples}

Histological samples from different areas of the intestinal mucosa were fixed with formalin. Paraffin sections were stained with haematoxylin-eosin, by the modified Gram method [8], and also with acridine orange for better detection of bacteria within the mucosa. Inflammatory changes in the mucosa were 
evaluated: solid lymphatic follicles and diffuse lymphatic infiltrate, infiltration by polymorphonuclear leucocytes (PMNLs), hyperaemia and mitotic activity. For diagnosis of pseudomembranous enterocolitis, several signs were taken into consideration: formation of pseudomembranes, haemorrhages, erosions of surface epithelium and inflammation in the lamina propria of the intestinal mucosa. The histopathological evaluation was done in a blinded manner on coded slides by two pathologists. These inflammatory changes were given a numerical score from $0=$ no changes to $5=$ severe changes [9].

\section{Bacteriological samples}

The quantitative composition of the luminal and mucosal microflora was estimated as described previously [10]. The counts $\left(\log _{10} \mathrm{cfu} / \mathrm{g}\right)$ of the principal groups of intestinal microbes (coliforms, enterococci, staphylococci, lactobacilli, peptostreptococci, clostridia, bacteroides, yeasts) and the total counts of aerobes and anaerobes were estimated. For better characterisation of the mucosal microflora, the predominant microbes were determined. A microbial group was considered as predominant if its proportion in the total count of mucosal microflora was $>30 \%$ in at least two animals of the same study group [11].

For bacteriological detection of bacterial translocation the homogenised samples from spleen, liver, mesenteric lymph nodes and heart blood were seeded onto blood agar (Blood Agar Base No. 2, Oxoid) and Fastidious Anaerobe Agar (FAA, Lab M). Blood agar was incubated for $48 \mathrm{~h}$ in an aerobic atmosphere and FAA in an anaerobic atmosphere (AnaeroGen and AnaeroJar, Oxoid) for 5 days. The bacteria were identified to genus level.

Toxin A was detected in the caecal content of killed hamsters by the sandwich immunoassay $C$. difficile Toxin A Test (Oxoid).

\section{Statistical analysis}

For detection of significant differences in score values of pathological changes and in the counts of microbes the data were analysed by the Mann-Whitney rank sum test with the 'Statgraphics' programme.

\section{Results}

\section{Development of $C$. difficile infection}

In the first study, all mice in the control group (group 1) and the cefoxitin-influenced group (group 2) survived and remained healthy. No symptoms of infection were discovered in animals challenged with C. difficile (group 3), although the intestines of all mice became colonised by $C$. difficile as estimated by bacteriological detection of $C$. difficile in faecal samples on days 2 and 5 .

In the second experiment, the hamsters that received ampicillin and $C$. difficile (group 4) all developed pseudomembranous enterocolitis. Affected caeca became distended with watery stool, congested and haemorrhagic. Lesions occurred in the caecum and terminal ileum. Colons of affected animals contained no formed stool. Hamsters died or became moribund within 1.5-2.5 days. Among hamsters who received lactobacilli and xylitol (group 5) only one of five animals developed enterocolitis within 3 days. No symptoms of enterocolitis were revealed in the other four hamsters in this group.

\section{Histological studies of intestinal mucosa}

The colonic mucosa of most group 1 mice showed no pathological changes: intact epithelium with regular crypts without infiltration, narrow blood vessels and low mitotic activity were observed. Mild hyperaemia and enlarged lymphoid follicles were observed in only one animal. Several solid lymphoid follicles, diffuse infiltrate, PMNLs and hyperaemia were found in the colonic mucosa of group 2 and 3 mice. In group 2 mice these changes were mild, but were moderately expressed in group 3 (Table 1). In some group 3 animals mitotic activity was also enhanced. Similar pathological changes, although less well developed, were found in ileal samples. Gram-positive and -negative bacteria were visible in the lumen of the gut, but never within the mucosa.

Signs of serious enterocolitis were present in all group 4 hamsters: i.e., infiltration with lymphocytes and PMNLs, erosions of epithelial surface, haemorrhages in mucosa and formation of pseudomembranes (Fig. 1a). These changes were equally expressed in

Table 1. The results of histological examination of colonic mucosa of control (group 1), antibiotic-compromised (group 2) and antibiotic-compromised and $C$. difficile-challenged mice (group 3)

\begin{tabular}{|c|c|c|c|c|c|}
\hline \multirow[b]{2}{*}{ Group of animals (n) } & \multicolumn{5}{|c|}{ Ranges (and medians) score values } \\
\hline & Lymphoid follicles & Lymphoid infiltrate & PMNL & Hyperaemia & Mitotic activity \\
\hline Group 1 (7) & $0-1(0)$ & $0(0)$ & $0(0)$ & $0-1(0)$ & $0(0)$ \\
\hline Group $2(8)$ & $0-2(1)$ & $0-2(1)$ & $0-2(1)$ & $0-2(0)$ & $0(0)$ \\
\hline Group $3(7)$ & $1-4(2)$ & $0-3(1)$ & $1-2(2)$ & $0-2(1)$ & $0-1(1)$ \\
\hline
\end{tabular}

Statistically significant difference between groups $(\mathrm{p}<0.01)$ : in lymphoid follicles, group 1 versus 2 and 3 and 2 versus 3 ; lymphoid infiltrate, group 1 versus 2 and 3; PMNL, group 1 versus 2 and 3; hyperaemia, group 1 versus 2 and 3 and 2 versus 3 ; mitotic activity, 3 versus 1 and 2 . 
terminal ileum and caecum, but to a lesser degree in colon. Gram-positive rods adhering to the mucosa were detected (Fig. 1b and c). In some cases bacteria were also detectable within the mucosa (Fig. 1d). Similar findings were present in one hamster from group 5, but no pseudomembranous enterocolitis was observed in the other four hamsters in this group and only mild inflammatory changes were detected in their intestinal mucosa (Fig. 1e). There were clear differences in the degree of infiltration, hyperaemia and haemorrhages, which were present significantly more often in group 4 hamsters than in group 5 animals
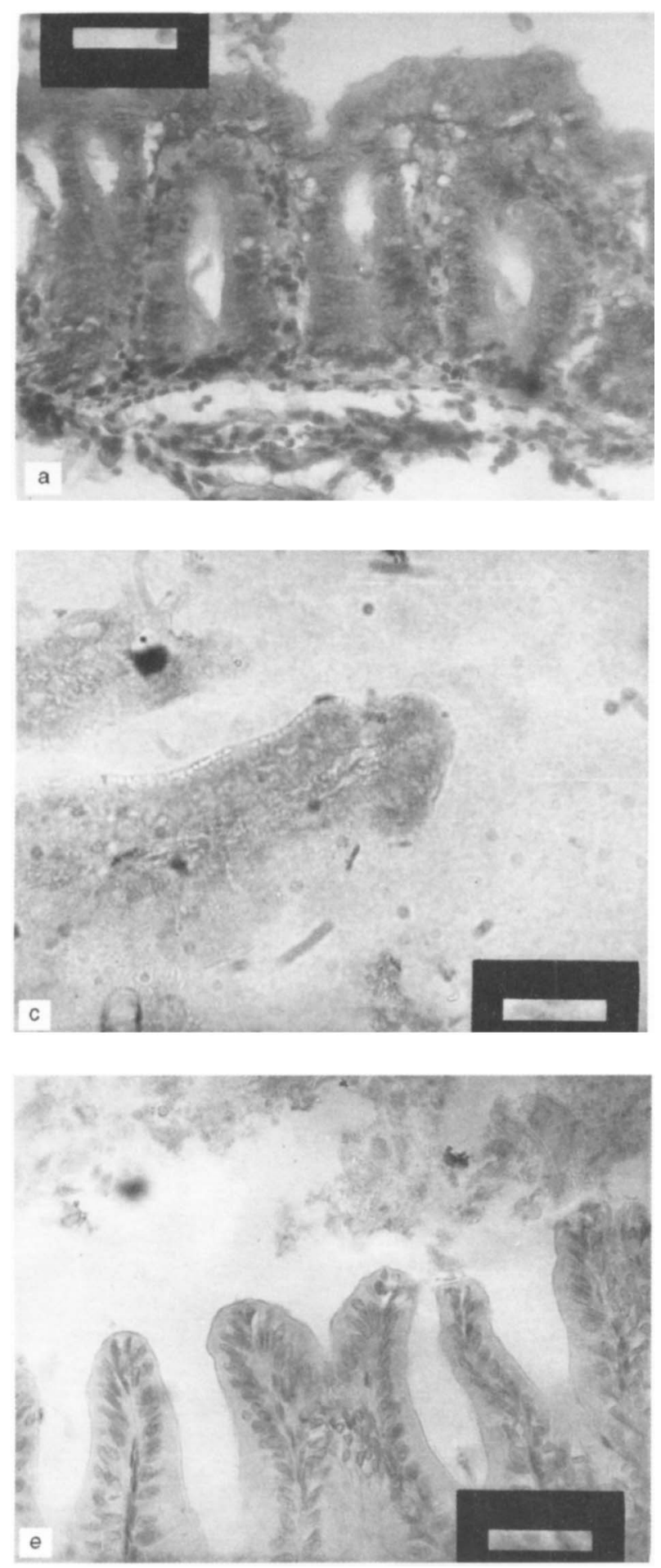

(Table 2). MNLs, destruction of tissue and pseudomembranes were found in higher score values in $C$. difficle-challenged hamsters without treatment with lactobacilli and xylitol than in treated animals.

\section{Bacteriological studies of intestinal microflora}

Details of the changes in luminal and mucosal intestinal microflora of the same experimental mice have been described in a previous paper [9]. After administration of cefoxitin (mice, group 2) both an absolute and a relative decrease in total anaerobes and
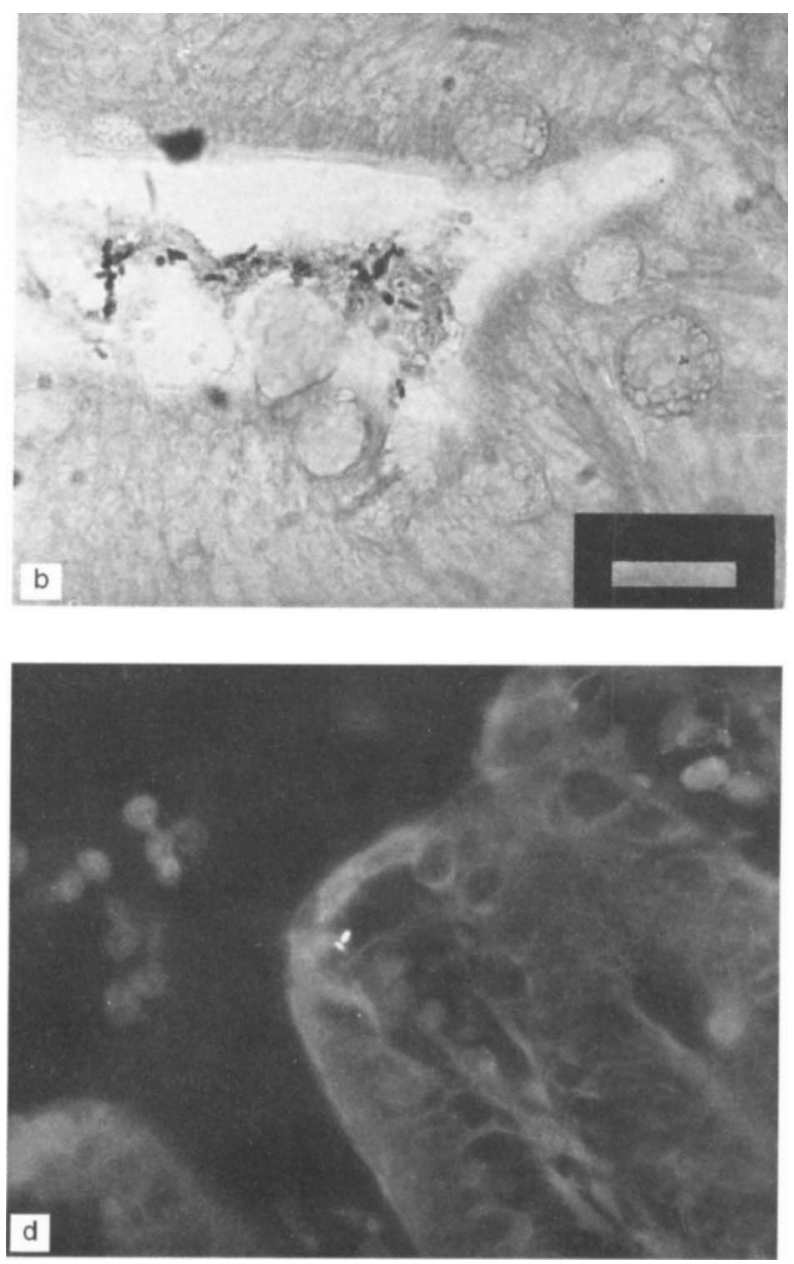

Fig. 1. Caecal mucosa of ampicillin-compromised and $C$. difficile-challenged hamsters: (a-d, group 4 hamsters with pseudomembranous enterocolitis; e, group 5 hamster without pseudomembranous enterocolitis). a, The lamina propria is inflamed, the surface epithelium is focally eroded. Adherent to the mucosal surface is an obvious inflammatory pseudomembrane. Areas of haemorrhage are not shown (haematoxylin-eosin, $\times 400$ ). b, Grampositive rods and other morphotypes of bacteria in the crypt base (modified Gram's stain, $\times 1000$ ). c, Grampositive rods adherent to mucosal surface (modified Gram's stain, $\times 1000$ ). d, Few bacteria within the caecal mucosa (stained with acridine orange, UV microscopy, $\times 1000$ ). e, Regular short crypts and smooth epithelial cell surface. In some animals mild inflammatory changes (hyperaemia and infiltration) could be seen (haematoxylin-eosin, $\times 400$ ). 
Table 2. The results of histological examination of ileal mucosa of $C$. difficile-infected hamsters receiving (group 5) or not receiving (group 4) lactobacilli and xylitol

\begin{tabular}{llll}
\hline & \multicolumn{3}{c}{ Range (median score values) } \\
\cline { 2 - 4 } $\begin{array}{l}\text { Inflammatory } \\
\text { changes }\end{array}$ & $\begin{array}{l}\text { Group 4 } \\
(\mathrm{n}=4)\end{array}$ & $\begin{array}{l}\text { Group 5 } \\
(\mathrm{n}=5)\end{array}$ & $\mathrm{p}$ value \\
\hline Infiltration & $4-5(5.5)$ & $1-4(2)$ & 0.03 \\
PMNL & $3-5(3.5)$ & $1-4(2)$ & 0.07 \\
Hyperaemia & $3-4(3)$ & $0-3(1)$ & 0.04 \\
Haemorrhages & $2-4(2.5)$ & $0-2(0)$ & 0.03 \\
Destruction & $1-3(1.5)$ & $0-2(0)$ & 0.07 \\
Pseudomembranes & $1-2(2)$ & $0-2(0)$ & 0.06 \\
\hline
\end{tabular}

their different subgroups occurred in ileum and colon (medians 0 and 0 versus 6.8 and $9.3 \log _{10} \mathrm{cfu} / \mathrm{g}$ in control mice, $\mathrm{p}<0.01$ ). Counts of enterococci were increased in the ileal mucosa and lumen of group 2 mice (medians 4.4 and 8.5 versus 0 and $6 \log _{10} \mathrm{cfu} / \mathrm{g}$ in controls, $p<0.01)$. These changes in intestinal microflora had partially recovered in group 3 mice, as they were killed 6 days after administration of the last dose of cefoxitin. All animals in this group were colonised by $C$. difficile.

The hamsters were further divided into two groups according to the development of fatal disease and pathological findings in the intestinal mucosa - with and without enterocolitis. The most important difference in the intestinal microflora between hamsters with and without enterocolitis was revealed in the counts of indigenous anaerobes (i.e., other than $C$. difficile) (Fig. 2). Indigenous anaerobes were absent from all mucosal samples of ileum and colon in hamsters with enterocolitis, and were present in only two samples of caecum. In luminal samples, indigen-

ous anaerobes were no longer the predominant microbes in these hamsters. C. difficile was present in high counts $\left(6.0-11.3\right.$, median $\left.7.6 \log _{10} \mathrm{cfu} / \mathrm{g}\right)$ in all luminal samples tested. In mucosal samples, $C$. difficile was absent from the ileum of only two animals (counts $0-7.0$, median $4.8 \log _{10} \mathrm{cfu} / \mathrm{g}$ ); toxin A was also present in their caecal content. In these hamsters, coliforms were the group of aerobic and facultative organisms present in highest numbers in most intestinal loci. The counts of coliforms in colonic content were 8.3-10.3 (median 9.0) and in mucosa $4.3-7.3$ (median 6.3) $\log _{10} \mathrm{cfu} / \mathrm{g}$.

In hamsters without enterocolitis, indigenous anaerobes were the predominant microbes in all sampled intestinal loci in both lumen and mucosa. C. difficile was detectable in low counts in two of these animals: in the ileal and caecal lumen in one hamster (3.3 $\log _{10} \mathrm{cfu} / \mathrm{g}$ ) and in the colonic lumen in the other animal $\left(4.3 \log _{10} \mathrm{cfu} / \mathrm{g}\right)$. Toxin $\mathrm{A}$ was not detectable in the caecal content of these hamsters.

\section{Bacterial translocation}

In mice bacterial translocation was most frequent in antibiotic-compromised mice in group 2 (Table 3). No translocation was detected in the control group (group 1). The most frequently translocating bacteria were lactobacilli and enterococci, and in two animals the lactobacilli were found even in blood cultures. Lactobacilli were also the predominant microbes in the ileal mucosa in all groups of mice.

In hamsters, bacterial translocation was more frequent in animals with pseudomembranous enterocolitis (all animals from group 4 and one animal from group 5,

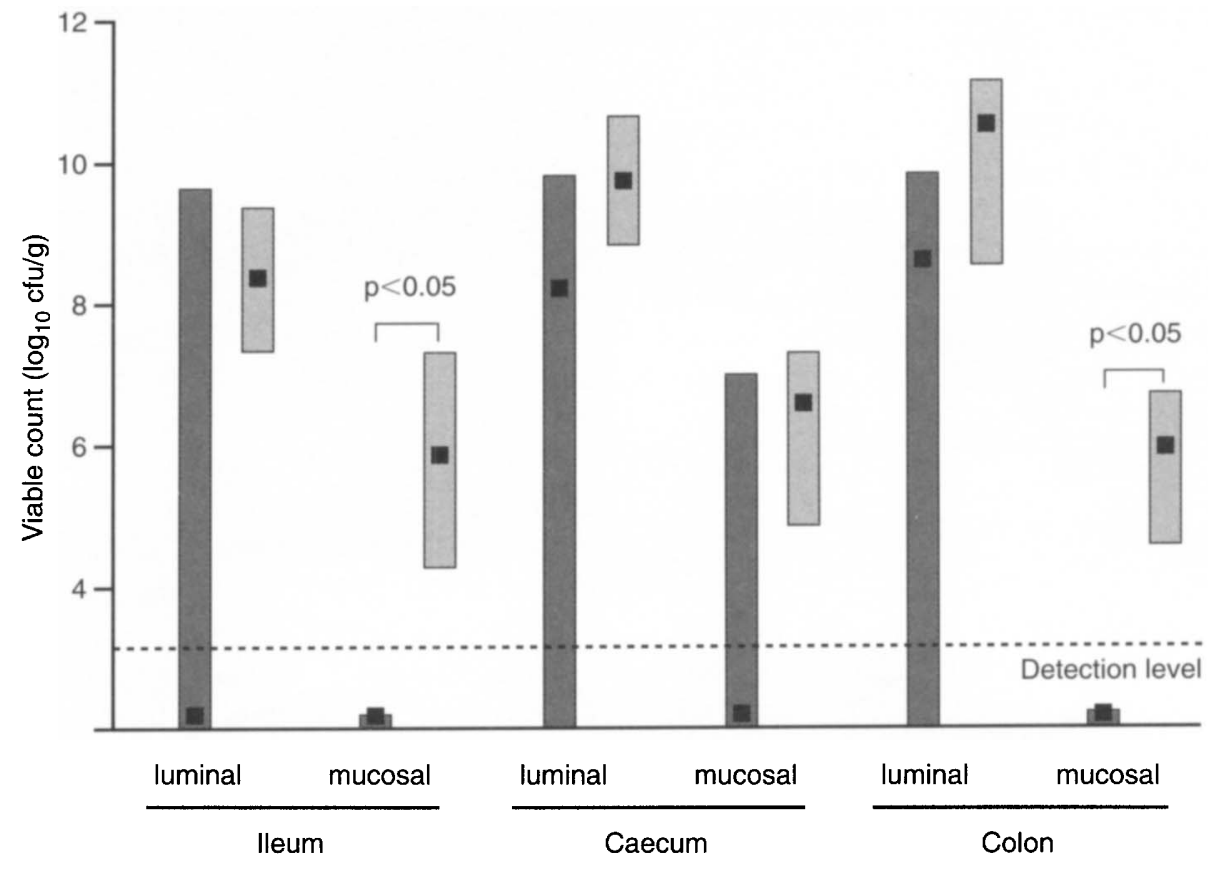

Fig. 2. Counts (ranges and medians, $\mathbf{\square}, \log _{10} \mathrm{cfu} / \mathrm{g}$ ) of indigenous anaerobes in different loci of hamsters with $(\mathrm{n}=5$, and without $(n=4$, 줎 $)$ enterocolitis. 
Table 3. Number of cases of translocation and mucosal predominance of intestinal microbes in mice in groups 1,2 and 3

\begin{tabular}{|c|c|c|c|c|c|c|}
\hline \multirow[b]{2}{*}{ Bacteria } & \multicolumn{2}{|c|}{ Group 1} & \multicolumn{2}{|c|}{ Group 2} & \multicolumn{2}{|c|}{ Group 3} \\
\hline & Translocation & Predominance & Translocation & Predominance & Translocation & Predominance \\
\hline Bacteroides & - & $\begin{array}{l}\text { Ileum } \\
\text { Colon }\end{array}$ & - & $\cdots$ & - & Colon \\
\hline Lactobacilli & - & $\begin{array}{l}\text { Ileum } \\
\text { Colon }\end{array}$ & $\begin{array}{ll}3 & \text { MLN } \\
1 & \text { Spleen } \\
1 & \text { Liver } \\
2 & \text { Blood }\end{array}$ & Ileum & $1 \mathrm{MLN}$ & $\begin{array}{l}\text { Ileum } \\
\text { Colon }\end{array}$ \\
\hline Enterococci & - & $\ldots$ & $\begin{array}{l}1 \text { MLN } \\
1 \text { Liver }\end{array}$ & $\begin{array}{l}\text { Ileum } \\
\text { Colon }\end{array}$ & - & $\cdots$ \\
\hline Yeasts & - & $\ldots$ & $1 \mathrm{MLN}$ & Ileum & - & Ileum \\
\hline
\end{tabular}

MLN, mesenteric lymph nodes.

Table 4. Number of cases of translocation and mucosal predominance of intestinal microbes in hamsters with and without enterocolitis

\begin{tabular}{|c|c|c|c|c|}
\hline \multirow[b]{2}{*}{ Bacteria } & \multicolumn{2}{|c|}{ With enterocolitis $(n=5)$} & \multicolumn{2}{|c|}{ Without enterocolitis $(n=4)$} \\
\hline & Translocation & Predominance & Translocation & Predominance \\
\hline Anaerobic gram-positive cocci & - & $\cdots$ & $1 \mathrm{MLN}$ & $\begin{array}{l}\text { Ileum } \\
\text { Colon }\end{array}$ \\
\hline Bacteroides & - & $\cdots$ & $\begin{array}{l}1 \text { MLN } \\
1 \text { Spleen } \\
1 \text { Liver }\end{array}$ & $\begin{array}{l}\text { Ileum } \\
\text { Caecum } \\
\text { Colon }\end{array}$ \\
\hline C. difficile & $\begin{array}{l}1 \text { MLN } \\
1 \text { Spleen }\end{array}$ & $\begin{array}{l}\text { Ileum } \\
\text { Caecum } \\
\text { Colon }\end{array}$ & - & $\ldots$ \\
\hline Lactobacilli & $\begin{array}{ll}1 & \text { MLN } \\
1 & \text { Spleen } \\
2 & \text { Liver }\end{array}$ & $\begin{array}{l}\text { Ileum } \\
\text { Caecum }\end{array}$ & $\begin{array}{ll}1 & \text { MLN } \\
1 & \text { Spleen } \\
1 & \text { Liver }\end{array}$ & $\cdots$ \\
\hline Enterococci & 2 MLN & $\begin{array}{l}\text { Ileum } \\
\text { Caecum } \\
\text { Colon }\end{array}$ & - & $\cdots$ \\
\hline Coliforms & $\begin{array}{l}3 \text { MLN } \\
4 \text { Spleen } \\
4 \text { Liver }\end{array}$ & $\begin{array}{l}\text { Ileum } \\
\text { Caecum } \\
\text { Colon }\end{array}$ & - & $\cdots$ \\
\hline
\end{tabular}

MLN, mesenteric lymph nodes.

Table 4). In most cases the translocated bacteria were coliforms, but in some cases enterococci and lactobacilli were also involved. In two animals $C$. difficile was also translocated to MLN and spleen. In hamsters without enterocolitis, translocation occurred more rarely and in most cases involved indigenous anaerobes (i.e., anaerobes other than $C$. difficile) and lactobacilli. L. rhamnosus GG was not found among translocating lactobacilli, despite the fact that it was present in cultures from intestines of group 5 hamsters.

\section{Discussion}

This study shows that both changes in intestinal microflora and mucosal status can influence bacterial translocation. In the mouse model, bacterial translocation was most frequent in animals that had not been infected by $C$. difficile, but whose intestinal microflora was more deeply disturbed because of recent administration of antibiotics (group 2). The translocating bacteria were lactobacilli and enterococci, i.e., bacteria predominating in the mucosal microflora after antibiotic treatment. In $C$. difficile-challenged mice (group 3 ), with more pronounced inflammation in the intestinal mucosa, translocation was rarer, as their indigenous intestinal microflora had been partly recovered because a longer time period had elapsed since the cessation of antibiotic treatment. Thus, it seems that in cases of mild $C$. difficile infection the extent of disturbance in the intestinal microflora is more important for promoting bacterial translocation than the degree of inflammatory activity in the mucosa. However, this study found some inflammatory changes in the intestinal mucosa of mice that had received antibiotic but not $C$. difficile. This inflammatory reaction could be caused by an imbalance of the micro-ecosystem and subsequent changes in metabolic end-products of micro-organisms or associated directly with the antibiotic. It is possible that these changes in the mucosa, induced by microflora shifts, also represent one of the co-factors supporting translocation.

In hamsters with fatal enterocolitis $C$. difficile was 
found in high numbers in most intestinal loci. In these animals with profound intestinal mucosal damage, bacterial translocation was detected in all cases. Translocating bacteria (coliforms, lactobacilli, enterococci and $C$. difficile) were also predominant in the intestinal mucosa. In hamsters that did not develop enterocolitis because of the administration of lactobacilli and xylitol, translocation was rare and usually caused by bacteroides and anaerobic cocci normally predominating in the intestinal mucosa and luminal content. Although these hamsters were fed lactobacilli, these microbes did not become predominant in their mucosal flora. The finding that the probiotic strain used did not become predominant in the intestinal microflora correlates with previous clinical studies [12].

Comparison of translocation in mouse and hamster models revealed several differences. Translocation following $C$. difficile infection was rare in mild infection in mice, but frequent in fatal pseudomembranous enterocolitis in hamsters. In mice, enhanced translocation was observed shortly after cessation of antibiotic treatment. In these mice, the most frequent translocating bacteria were lactobacilli and enterococci, but in $C$. difficile-infected hamsters, coliforms were most frequently found. This could be explained by differences in their intestinal microflora: in cefoxitintreated mice, enterococci and lactobacilli become predominant in intestinal content, as well as in the mucosa, and the counts of coliforms remain relatively low, but in hamsters after ampicillin treatment, coliforms reached very high numbers in all intestinal loci studied. Translocation of $C$. difficile was observed in only a few cases of fatal enterocolitis in hamsters. It seems that despite its presence in high numbers in the intestine, $C$. difficile can translocate rarely and only when there has been serious damage to the intestinal mucosa. Also, in clinical studies $C$. difficile has rarely been found in blood and other extraintestinal sites [13].

The findings that changes in intestinal micro-ecology, i.e., reduction of colonisation resistance due to suppression of indigenous microflora and overgrowth by some subordinate bacteria, can promote bacterial translocation from the intestinal tract correlates with previous data $[5,14]$. In the present study, the translocating bacteria were in all cases also the predominant microbes in the intestinal mucosa. This finding correlates with previous experiments [11]. Clinical studies have also shown that in most cases of bacteraemia due to bacterial translocation from the intestinal tract, the causative agent is the same facultative gram-negative organism that was found to be predominant in faeces [4]. It has been shown that C. difficile-associated diarrhoea is a predisposing factor for gram-positive bacteraemia, especially with Enterococcus spp. [15]. Enterococci are typically resistant to many antimicrobial agents and, therefore, may survive the antimicrobial treatment inducing $C$. difficile diarrhoea and overgrow after reduction of colonisation resistance. Although it is known that some microbes are more capable of translocation than others, it seems that in the case of antibioticassociated diarrhoea, the composition of individual intestinal microflora and the spectrum of activity of the antibiotic used are the most important factors in selecting a micro-organism that can potentially translocate and cause bacteraemia.

This study revealed that the combination of lactobacilli and xylitol has some protective effect against $C$. difficile infection. Four of five hamsters receiving probiotics remained healthy, and the inflammatory changes in their intestinal mucosa were milder. Previously published experiments have shown that the susceptibility or resistance of hamsters to $C$. difficile is absolute [16]. Partial susceptibility, manifesting itself in the form of mild illness or prolonged diarrhoea, has not been observed. Thus, clear-cut endpoints can be obtained without using large numbers of animals. For instance, in a previous study, four or five out of five animals in each experimental group either remained completely healthy or developed typical symptoms of enterocolitis within 3-5 days [17]. These data are in good agreement with the present study.

It has been shown that administration of L. rhamnosus GG could be used for the treatment of recurrent $C$. difficile colitis $[18,19]$. Xylitol, a non-absorbable sugar, appears to be a stable substrate for intestinal lactic acid bacteria [20]. On the other hand, previous experiments have shown that xylitol itself can also inhibit the adhesion of $C$. difficile to $\mathrm{CaCo}-2$ cells [21]. Further experiments are needed to study the possibilities of application of probiotics combined with substrate for the treatment and prophylaxis of $C$. difficile infection.

It can be concluded from these results that in cases of mild $C$. difficile diarrhoea, alteration of mucosal indigenous microflora and overgrowth by some resistant facultative aerobes is more important for promoting translocation than the presence of inflammation in the mucosa. Serious destruction of the intestinal mucosa caused by pseudomembranous enterocolitis leads to massive polymicrobial translocation by the predominant mucosal microflora. Thus, in patients with a serious underlying disease whose intestinal microflora has been disturbed by antimicrobial therapy, the detection and sensitivity testing of overgrowing facultative flora could be important for predicting the possible cause of sepsis and selecting appropriate empirical antimicrobial therapy. Application of probiotics with suitable substrates to restore the indigenous intestinal microflora may also be useful for the prevention of bacterial translocation from the intestinal tract in these patients. 
We thank Endel Türi (MD) and Jaana Simso for assistance with histological methods and interpretation of the morphological changes.

\section{References}

1. Borriello SP. Possible mechanisms of action of antimicrobial agent-associated gastrointestinal symptoms. Postgrad Med J 1992; 68 Suppl 3: S38-S42.

2. Tabaqchali S, Jumaa P. Diagnosis and management of Clostridium difficile infection. BMJ 1995; 310: 1375-1380.

3. Morris JB, Zollinger RM, Stellato TA. Role of surgery in antibiotic-induced pseudomembranous enterocolitis. Am J Surg 1990; 160: 535-539.

4. Wells CL, Maddaus MA, Simmons RL. Proposed mechanisms for the translocation of intestinal bacteria. Rev Infect Dis 1988; 10: $958-979$.

5. Berg RD. Translocation of enteric bacteria in health and disease. In: Cottier H, Kraft $\mathrm{R}$ (eds) Gut-derived infectioustoxic shock (GITIS). Curr Stud Hematol Blood Transfus. (59) Basel, Karger. 1992: 44-65.

6. Wilson $\mathrm{KH}$, Sheagren $\mathrm{N}$, Freter R, Weatherbee L, Lyerly D Gnotobiotic models for study of the microbial ecology of Clostridium difficile and Escherichia coli. J Infect Dis 1986; 153: 547-551.

7. May T, Mackie RI, Garleb KA. Effect of dietary oligosaccharides on intestinal growth of and tissue damage by Clostridium difficile. Microecol Ther 1995; 23: 158-170.

8. Brown RC, Hopps HC. Staining of bacteria in tissue sections: a reliable gram stain method. Am J Clin Pathol 1973; 60: 234-240.

9. Axelsson L-G, Midtvedt T, Bylund-Fellenius A-C. The role of intestinal bacteria, bacterial translocation and endotoxin in dextran sodium sulphate-induced colitis in the mouse. Microb Ecol Hlth Dis 1996; 9: 225-237.

10. Naaber P, Mikelsaar M. Antibiotic-compromised murine model of Clostridium difficile infection. Microecol Ther 1995; 25: 201-205.

11. Mikelsaar M, Türi E. Effect of antibacterial drugs and dental surgery on the translocation of digestive tract microflora. Microecol Ther 1990; 20: 93-97.

12. Sepp E, Mikelsaar M, Salminen S. Effect of administration of Lactobacillus casei strain GG on the gastrointestinal microbiota of newborns. Microb Ecol Hlth Dis 1993; 6: 309-314.

13. Feldman RJ, Kallich M, Weinstein MP. Bacteremia due to Clostridium difficile: case report and review of extraintestinal C. difficile infections. Clin Infect Dis 1995; 20: 1560-1562.

14. Van Leeuwen PAM, Boermeester MA, Houdijk APJ et al. Clinical significance of translocation. Gut 1994; Suppl 1: S28-S34.

15. Borek A, Kelly P, Hacek D, Dressel D, Kruszynski J, Peterson L. The incidences of bacteremia associated with detection of Clostridium difficile in 120 patients over a 30-month period. In: Congress on Anaerobic Bacteria and Anaerobic Infections Abstract Book. Chicago, Anaerobe Society of Americas. 1996.

16. Larson HE, Borriello SP. Quantitative study of antibioticinduced susceptibility to Clostridium difficile enterocecitis in hamsters. Antimicrob Agents Chemother 1990; 34: 1348-1353.

17. Larson HE, Welch A. In-vitro and in-vivo characterisation of resistance to colonisation with Clostridium difficile. $\mathrm{J} \mathrm{Med}$ Microbiol 1993; 38: 103-108.

18. Biller JA, Katz AJ, Flores AF, Buie TM, Gorbach SL. Treatment of recurrent Clostridium difficile colitis with Lactobacillus GG. J Pediatr Gastroenterol Nutr 1995; 21: 224-226.

19. Gorbach SL, Chang T-W, Goldin B. Successful treatment of relapsing Clostridium difficile colitis with Lactobacillus GG. Lancet 1987; 2: 1519.

20. Salminen S, Salminen E, Koivistoinen P, Bridges J, Marks V. Gut microflora interactions with xylitol in the mouse, rat and man. Food Chem Toxicol 1985; 23: 985-990.

21. Naaber P, Lehto E, Salminen S, Mikelsaar M. Inhibition of adhesion of Clostridium difficile to Caco-2 cells. FEMS Immunol Med Microbiol 1996; 14: 205-209. 